\title{
HISTÓRIAS DE VIOLÊNCIA: ARTE PENSANTE EM FORMA DECOLONIAL BRAD EVANS ENTREVISTA LEWIS R. GORDON ${ }^{1}$
}

\author{
HISTORIES OF VIOLENCE: THINKING ART IN A DECOLONIAL WAY \\ BRAD EVANS INTERVIEWS LEWIS R. GORDON
}

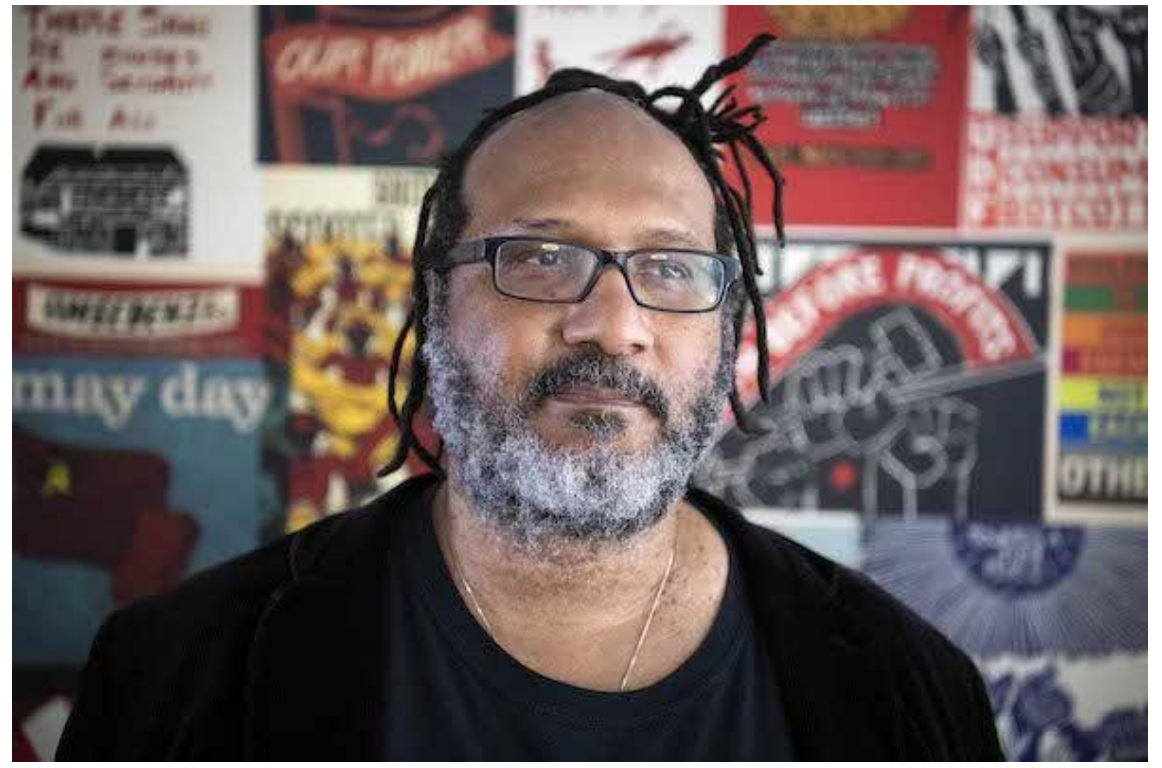

3 de junho de 2019

Por Brad Evans ${ }^{2}$

Tradução de Rosemere Ferreira da Silva ${ }^{3}$

ESTE É O THE $2^{\circ}$ uma série de diálogos com artistas, escritores, pensadores críticos sobre a questão da violência. Esta conversa é com Lewis R. Gordon, professor de Filosofia com filiação em Estudos Judaicos, Estudos Caribenhos e Estudos Latino-Americanos, Estudos Asiáticos, Estudos Asiáticos Americanos e Estudos Internacionais na UCONN-

1 Publicação originalmente na The Los Angeles Review of Books, 3 de junho de 2019. https://lareviewofbooks.org/article/histories-of-violence-thinking-art-in-a-decolonial-way/ Tradução de Rosemere Ferreira da Silva; permissão de tradução de Brad Evans e Lewis R. Gordon. A introdução do entrevistado por Brad Evans permanece na tradução abaixo da data da publicação da entrevista conforme publicação original.

2 Brad Evans Brad Evans é um filósofo político, crítico teórico e escritor especializado no problema da violência. Ele é o fundador / diretor do projeto Histories of Violence , que tem uma base de usuários global que abrange 143 países.

${ }^{3}$ Profa. Titular do Departamento de Ciências Humanas- Campus V da Universidade do Estado da Bahia (UNEB). E-mails: rosefsilva@uneb.br ou roserosefr2000@yahoo.com.br. 


\section{Storrs. Entre as suas publicações inclui-se What Fanon Said: A Philosophical Introduction to His Life and Thought (2015) e o título a ser publicado Fear of Black Consciousness.}

BRAD EVANS: Você descreveu a arte como sendo "a expressão de seres humanos criados e pertencidos em um mundo que realmente não precisava nos ter". Essa compreensão da arte, que está em marcante contraste com a arte como a produção de fetichização de mercadorias, tem uma profunda influência em sua relevância para a condição humana, especialmente sua violência. Dada a definição oferecida, o que você entende ser a relação entre arte e violência?

LEWIS R. GORDON: Eu rejeito o modelo de arte como a produção de fetichização de mercadorias. Não é que a arte nunca possa ser mercantilizada ou transformada em fetiche. Minha objeção é que a história da arte nos é apresentada apenas sob condições sociais específicas. A sociedade Euro moderna e sua celebração do capital são apenas partes da história humana. É decadente reduzir a arte a um único elemento daquilo que às vezes fazemos com ela - ou seja, arte para consumo.

Tal relato de arte é também uma forma de arrogância europeia onde nada existe exceto através de ações de europeus ou brancos. A antiga humanidade decorada encontrou maneiras de temperar sua comida, fazer música e dançar. Alguns faziam isso de maneira ritualística; outros o fizeram por razões instrumentais há muito perdidas para o resto de nós; e outros o faziam simplesmente por satisfação, diversão ou prazer. A Europa certamente não inventou a ideia de uma "vida boa".

No entanto, a questão subjacente é: por que fazer isso? Mesmo que gostemos de fazer algo, às vezes temos que ser persuadidos nessa atividade. Eu considero nossa espécie e talvez alguns dos nossos primos aparentados, mas agora extintos, dotados de um extraordinário senso de consciência e possibilidades críticas que assombram cada momento de investimento vivido. $\mathrm{O}$ fato de que nos confundimos com o que nos precedeu e o que nos sucederá traz à tona o enigma existencial do que trazemos à realidade como necessário, apesar de nossa existência ser contingente. Para alguns, isso ocasiona medo e tremor. Para outros, maravilha. E sim, há aqueles que estão ocupados demais para se importar. No entanto, até mesmo o último achado pausa por momentos em meio ao fluxo e refluxo da vida na gama de experiências estéticas que temos com objetos e performances que chamamos de "arte. "A arte traz valor à nossa existência em um mundo através da radicalidade de nossa não necessidade. Em outras palavras, porque somos irrelevantes para a realidade, isso significa que nosso valor, através da arte, deve estar em nossos termos. A arte nos permite viver apesar da realidade e infinitas possibilidades do absurdo - incluindo a noção absurda de que nossa existência é necessária.

A relação entre arte e violência, como eu vejo, é de valor, valorização e validade. A ideia central é que a violência existe de maneira apropriada onde existe um valor atribuível, que é tanto aceito como negado na ação violadora. Acidentalmente entrar em uma parede dói. Alguém 
empurrando você em uma parede é violência. Este último oferece duas formas de sofrimento, enquanto o primeiro tem apenas uma. Os dois são dor e degradação. Ser valorizado é perceberse como fonte de valor e, experimentar valorizar é oferecer dignidade. Violência arranca essa dignidade. Quando emerge de fontes não ligadas ao mundo humano de valor comunicado e comunicável, há um acidente. Embora possa ser contingente que a violência nos aconteça nunca é acidental. Onde há violência, há, então, responsabilidade.

A arte, entre outras características da vida humana, é um valor fundamental para a radicalidade dos valores em que nos é oferecido um refúgio da desolação. Isso, no entanto, nos torna vulneráveis à experiência de sermos jogados de volta ao vazio frio e indiferente. Existe, portanto, um elemento empoderador na arte que, paradoxalmente, também se liga ao significado violento do desempoderamento.Toda violência inclui o desempoderamento do outro.

BE: Em termos de sua compreensão crítica, em vez de focar nas práticas coloniais da arte, você destaca as formas pelas quais o colonialismo é trazido à arte como uma força invasiva. A este respeito, poderíamos ver a arte como sendo, por definição, algo que é necessariamente anticolonial e de fato revelador de algo pré / pós-colonial na temporalidade de suas demandas e reivindicações sobre a liberação de modos nãoeurocêntricos de viver?

LRG: Sim. Meu argumento é aquele que vincula precisamente a arte à liberdade. Não é, no entanto, liberdade em si mesma. Está sempre alcançando além de si mesmo como um testemunho de nossa condição. É por isso que a excelente arte fala através das gerações. É apenas parcialmente no seu tempo. A arte ruim, no entanto, sofre de uma forma de implosividade. Isto, a propósito, é também como eu defino opressão. Ou, em outras palavras, a subjugação de uma vida é uma subjugação de suas artes de expressão. A vida humana prospera quando alcança além de si mesma. A opressão nos empurra de volta a nós mesmos, a ponto de ficarmos presos em nossos corpos e, eventualmente, a doenças mentais. O que é loucura, mas perder a cabeça? Eu também descrevo esse fenômeno como fechamento epistêmico. Significa não precisar mais aprender; saber pouco é saber tudo. Essa mentalidade poderia ser trazida para a arte. Colapsa arte ou práticas artísticas em formas de ídolos fechados. É isso que o colonialismo, o racismo e todas as formas de opressão fazem. É por isso que eles estão saturados de violência.

Ainda existe um paradoxo. O colonialismo e outras formas de opressão são, afinal de contas, práticas humanas através das quais as instituições humanas de violência são construídas e mantidas. O que isto significa é que elas nunca poderiam ser completas. São tentativas, como ídolos e expressões de idolatria, de fechar a realidade humana reduzindo-a a um de seus elementos. No caso do racismo, isso significa o narcisismo, como vimos nos últimos cem anos, da supremacia branca. As limitações óbvias de todos esses esforços são que mesmo aqueles que os construíram acabam por considerá-los inabitáveis e buscam alternativas até mesmo daqueles que supostamente "conquistaram". As pessoas colonizadas lutam e parte de sua resistência está 
em seus esforços para recuperar seu valor, muitas vezes através da produção da arte que transcende os ídolos que lhes são impostos. Arte colonial eventualmente sofre o destino de todos aqueles que imaginam que eles são o fim da arte, história e pensamento. Eles se tornam entediantes, sem imaginação, irrelevantes.

A história dos colonizadores que buscam criatividade por meio da fusão ou crioulização com a vida estética dos que dominam é bem conhecida. É também uma história mal compreendida. Muitos hoje chamam de "apropriação". Eu rejeito essa caracterização, uma vez que ela não consegue abordar o que significa participar do belo, agradável e profundo. Os melhores conceitos para usar são "apagamento histórico", "deturpação histórica" ou, indo direto ao ponto, "roubo histórico". Eu uso "histórico" em cada um porque a questão não é se alguns ou talvez muitos brancos, por exemplo, participaram das formas estéticas de não brancos. É que esses brancos exploraram a história e capitalizaram essas formas através da mercantilização, deturpação histórica e práticas de privação de direitos.

A liberação de formas não eurocêntricas de arte, então, é a liberação da arte. Eu vejo a libertação da arte como ligada à liberdade, uma vez que isso também exigiria a liberdade dos povos não europeus. O filósofo nativo americano V.F. Cordova argumenta muito bem com esse ponto: "O valor da sobrevivência é ser capaz de se reconhecer depois que você conseguiu sobreviver." Além de sobreviver à invasão colonial, as pessoas colonizadas levantam, através da arte, uma questão importante à humanidade, como sua arte é obrigada a enfrentar a violência desencadeada em todos nós de tal ataque: dado o que foi feito, o que nos tornamos? O que podemos, ao recordar, oferecer como testamentos de pertencimento?

"Pertencer" é, afinal de contas, uma palavra incomum. Na verdade, significa continuar sendo. Isso requer ter um lugar no reino do possível. O que isso exige além da liberdade?

BE: A influência de Frantz Fanon sobre o seu trabalho ainda permanece poderosa e instrutiva. Ao ler Fanon, muitas vezes sou tomado por sua linguagem poética e como sua crítica invoca uma imaginação verdadeiramente radical. Poderíamos, por exemplo, pegar um número inteiro de passagens de Black Skins, White Masks ou The Wretched of the Earth e lê-las como poemas em seus próprios termos. $O$ que é sobre Fanon, que ainda captura sua imaginação (pensando com e além de Fanon), especialmente em termos de suas qualidades poéticas e estéticas?

LRG: Fanon não era disciplinadamente decadente. Ele amava a liberdade e entendia que espremer a condição humana em uma única narrativa, em um só par de sapatos ou em uma só caixa, seria nos transformar em problemas. Seria uma forma de violência. Ele entendeu que isso não era uma questão de mudar de jogador. Foi - e continua a ser - mudar o jogo. Fazer isso significa mais do que o jogo, mas compreender como o jogo é jogado.

Fanon criticava a despersonalização, a dissociação, a desconexão e as variedades de formas pelas quais os seres humanos são expulsos das relações com a realidade - que se incluem mutuamente - no isolamento e na loucura dos eus contidos. Tal modelo é mais adequado para 
deuses, não pessoas. Os seres humanos exigem criatividade, o que, por sua vez, requer possibilidade e liberdade. Ele via assim o colonialismo e a opressão também em níveis metodológicos. É por isso que ele foi capaz de ver e articular a verdade para além dos limites da prosa filosófica e científica comum. Tais maneiras de oferecer a verdade escondem seu próprio caráter estético através de supostas alegações de não subjetividade. De fato, a divisão subjetiva versus objetiva é carregada de falácias, já que uma não poderia fazer sentido sem a outra.

Os talentos poéticos de Fanon são evidentes por toda parte. Além de seus conhecidos livros publicados antes de sua morte, há muitos ensaios, editoriais, poemas e até mesmo artigos de revistas acadêmicas com ressonância poética. Fanon entendeu que a profundidade não deveria ser um passivo, mas sim uma exemplificação da comunicabilidade. Então, também, deveria humor não ser uma responsabilidade. Os leitores ficam muitas vezes chocados com o quão engraçado ele é. Fanon, o revolucionário psiquiatra forense e clínico, não era apenas um homem de ação, mas alguém que encontrava tempo para cozinhar, dançar e ler romances, peças teatrais e poesia.

No espírito de Fanon, levo algumas dessas questões adiante e ofereço ideias por meio da composição musical e da performance, e também argumento que existem verdades disponíveis por meio de formas estéticas e que a teoria por si só é insuficiente para uma relação saudável com a realidade. Nós também precisamos de significado. Um problema com muito do que é oferecido como escrita científica e acadêmica profissional, por exemplo, é que eles são tentativas de desmitificar a realidade a ponto de oferecer uma teoria sem sentido. Eu exploro considerações como verdade na ficção, significado rítmico e muito mais. Assim, levo a sério a significância do significado do mito, da narrativa e sua importância para a comunicação e também a sensibilidade crítica. Em outras palavras, o mundo do pensamento sofre onde seu modelo é a desconexão, em vez da conectividade.

\section{BE: Então, o que faz o pensamento da arte de maneira decolonial no nível da prática estética cotidiana? E quais artistas contemporâneos, em particular, se destacam para você neste sentido, como se estivessem empurrando as fronteiras da imaginação colonial?}

LRG: Devemos ter em mente que a descolonização é sempre um ato ou momento de transição. É a transformação do dado com uma expectativa de abertura do que virá. Isto é um paradoxo porque onde se fetichiza seria uma forma de fechamento epistêmico. Com efeito, teria que produzir relações coloniais para manter as práticas decoloniais. Então, eu vejo apenas questões decoloniais como momentos críticos em certas formas de arte, mas não necessariamente os focos nos quais a arte deve se basear. Meu argumento sobre a arte é que ela não deve ser uma coisa, mas sim uma reunião ou convergência de muitos elementos através dos quais vivemos nossas relações com a realidade. Arte é, em outras palavras, sobre liberdade e pertença sem dissociação dos desafios da vida em face dos sem vida.

Dada a minha posição, eu exploro uma ampla gama do que chamamos de "arte" ao longo da existência humana. Tento conversar com nossos ancestrais que conseguiram nos oferecer 
inteligibilidade de afeto e verdade desde a antiguidade até o presente. Isso varia do visual ao auditivo e ao gastronômico - em suma, toda a gama do que é propriamente chamado de estética , que se refere a afetar todos os sentidos. Eu não esqueço a estética por causa da minha posição sobre as dimensões e possibilidades de significado proporcionadas na prática da arte, entre outros tipos de atividade criativa.

Assim, com um objetivo tão elevado, e dada a minha posição sobre a relacionalidade e as dimensões da liberdade da arte, devo primeiro enfatizar que busco essas experiências do radicalmente local e independente para o global. Como este é um fórum limitado, não vou insistir em nossa discussão com a longa lista de trabalhos que eu amo, mas em vez disso vou simplesmente focar em alguns praticantes vivos da música e da arte visual.

Eu imediatamente penso nos seguintes artistas no mundo da música: Michael Abels (Estados Unidos), Joan Baez (Estados Unidos), José Adelino Barceló de Carvalho (mais conhecido como Bonga de Angola), Peter Gabriel (Reino Unido), Abdullah Ibrahim (África do Sul), Linton Kwesi Johnson (Reino Unido e Jamaica), Joni Mitchell (Canadá), Meshell Ndegeocello (Estados Unidos), Youssou N'Dour (Senegal), Sinéad O'Connor (Irlanda), Burning Spear (também conhecido como Winston Rodney , Jamaica), Boubacar Traoré (mais conhecido como Kar Kar do Mali), Jagjit Singh (Índia), Tracy Chapman (Estados Unidos).

Eu vejo esses artistas como herdeiros de, se por "contemporâneo" você também quer dizer os últimos 50 anos, os afro-americanos John Coltrane, Alice Coltrane, Sam Cooke, Miles Davis, Marvin Gaye, Jimi Hendrix, Abbey Lincoln / Aminata Moseka, Charles Mingus , Thelonious Monk, Prince, Max Roach, Horace Silver, Nina Simone e Billy Strayhorn, o porto-riquenho Willie Colón, o canadense Leonard Cohen, o nigeriano Fela Kuti e os grupos jamaicanos Wailers, Abyssinians e Steel Pulse.

Esses artistas eram revolucionários. Cada um deles levou o mundo do gênero rejeitado e transcendido e práticas esperadas para oferecer retratos de liberdade, desespero, amor e tristeza. A lista entre aqueles que se tornaram ancestrais, é claro, não é exaustiva, e se eu fosse listar os últimos 200 anos, o que inclui artistas que eu ouço de muitos outros países, os leitores facilmente parariam de ler.

Como deveria ser evidente, eu não tenho a popularidade de alguns artistas contra eles. Você, sem dúvida, também percebe que existem alguns artistas "brancos" nessa lista não exaustiva. Sempre houve artistas brancos que desafiaram não apenas a colonização da arte, mas também o mesmo para a humanidade. Os artistas listados consideram seu compromisso com a liberdade em sua arte também como forma de resistência contra a colonização e outras formas de descolonização.

Costumo dizer que sou o cara que gosta do lado "B" dos álbuns. Perdeu a ressonância na era dos CDs e agora em MP3 e streaming. Pelo lado "B", quero dizer que a maior parte do que eu ouço é "indie" ou música produzida independentemente e a maior parte da minha visualização é de cinema independente. Existem, no entanto, "hits" que fazem a minha lista. Cineastas - isto 
é, diretores-redatores (novamente, entre os vivos) - incluem Charles Burnett, Haile Gerima, Marlon Riggs, Lina Wertmüller, Eudhan Palcy, Julie Dash, Rajkumar Hirani, Jordan Peele, Ryan Coogler e Boots Riley.

Há, é claro, artistas cujas obras nos conectam a temas de liberdade e pertencimento, apesar das forças do niilismo esmagador, sem oferecer o tema da descolonização. Esses artistas são muitos, e o fracasso de pelo menos engajar o que eles oferecem desmoronaria minha análise em um exemplo de fechamento estético e epistêmico. Muitos deles obtêm o proverbial "isto" da nossa existência, seja através do triste país do grupo indie espanhol Barbott ou do virtuosismo majestoso de Erykah Badu (escute suas gravações ao vivo) ou do guitarrista sul-africano de jazz Vuma Levin, o casal dinâmico, do saxofonista de jazz norte-americano Ben Barson e ópera, jazz, e o violonista e violoncelista americano-mexicano Gizelxanath Soprano, e a pianista de jazz japonesa Hiromi.

Também aguardo com expectativa a mídia mista de artistas visuais como a afro-americana Paula Wilson em Carrizozo, Novo México, e a salvadorenha Karina Alma (ex-Oliva Alvarado) em Los Angeles, Califórnia. Além disso, há projetos de teatro como o Rites \& Reason no Departamento de Estudos Africanos da Brown University, o Edinburgh Festival Fringe e o Makhanda (anteriormente Grahamstown) National Arts Festival, no qual os temas de nossa conversa são abundantes.

Devo salientar que o trabalho de Levin, Barson, Gizelxanath Soprano e Alma também abordam temas descoloniais. Minha lista de romancistas, poetas, dramaturgos, coreógrafos, arquitetos e chefs inovadores também faria essa discussão ir longe demais.

E, é claro, há muitos artistas sem nome que nos fazem parar enquanto se agitam nas ruas do mundo. Eles nos lembram que saímos do nada que criamos em algum lugar por meio da produção do que acabou sendo uma obra do anônimo para todos que são paradoxalmente valorizados, apesar de todos compartilharem o eventual destino do anonimato no momento do último suspiro de nossas testemunhas. 